\title{
Marginal abatement costs of greenhouse gas emissions from European agriculture, cost effectiveness, and the EU non-ETS Burden Sharing Agreement
}

\author{
Stéphane De Cara ${ }^{1}$ and Pierre-Alain Jayet ${ }^{2}$
}

We propose a quantitative assessment of the marginal abatement costs (MAC) of greenhouse gas emissions from European agriculture and analyze the implications of the non-ETS burden-sharing agreement (BSA) for this sector. This assessment is based on MAC reduced forms, the generic specification of which enables simple parameterization and numerical computations. Such MAC curves are parameterized for each Member State using the outputs of a detailed model of the European agricultural supply. They are then used to compute total and marginal abatement costs involved by the BSA targets, as well as the costeffective effort sharing, the corresponding emission price and abatement costs.

The main findings are: (i) flexibility mechanisms such as a cap-and-trade system for agricultural emissions could reduce the total costs of meeting the $10 \%$ EU abatement target by a factor two to three relative to the strict implementation of each country's target, (ii) the corresponding equilibrium emission price is found to be 32-42 €/tCO2eq depending on the assumption regarding business-as-usual emissions, and (iii) a cap-and-trade system with allowances based on the BSA targets would involve substantial transfers from EU-15 countries to New Member States, an important share of which being made of 'hot air'.

Keywords: Greenhouse gas emissions, Agriculture, Marginal abatement costs, Cap-and-trade system, Methane, Nitrous oxide, European Union

1. INRA, UMR 210 Economie Publique INRA-AgroParisTech, ThivervalGrignon, France

Corresponding author. INRA UMR Economie Publique INRA-

AgroParistech, BP01, F-78850 Thiverval-Grignon, France.

Tél: +33(0)130815348

stdecara@grignon.inra.fr

2. INRA, UMR 210 Economie Publique INRA-AgroParisTech, ThivervalGrignon, France

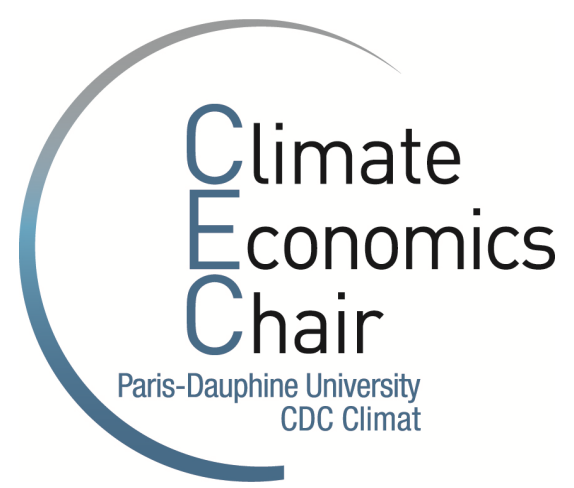





\section{Introduction}

According to the latest greenhouse gas (GHG) inventories by the EEA (European Environment Agency, 2010a), agricultural emissions represent about 10\% of total EU emissions. The role of this sector in cost-effective mitigation policies has been increasingly emphasized in the recent years (UNFCCC, 2008; Smith et al., 2008; European Commission, 2009). One important characteristic of agricultural emissions is that they result from the activities of a large number of small-scale emitters. Furthermore, the diversity in the conditions of production within and across countries leads to large heterogeneities in abatement costs. Such heterogeneities have important consequences on the design of cost-effective mitigation policies (De Cara et al., 2005).

The recent European Climate-Energy package sets ambitious targets for greenhouse gas (GHG) emission reductions (European Commission, 2008). To meet this objective, the European Commission has defined a two-tier strategy. On the one hand, GHG emissions from large-scale emitters, mostly in the industry and the energy sectors, are currently covered by a cap-and-trade system known as the European Trading System or ETS (European Union, 2003). On the other hand, emissions from the transport, residential, and agricultural sectors, which are much less concentrated and more difficult to monitor, are not subject to emission trading. In 2009, it was decided to reduce total EU emissions from the sectors currently not covered by the ETS by approximately $10 \%$ in 2020 relatively to 2005 levels. This decision was accompanied with a burden-sharing agreement (BSA), which sets Member-State specific targets for non-ETS emissions (European Union, 2009).

In the European decision regarding the BSA, cost-effectiveness was put forth as one out of six principles guiding the establishment of the Member-State targets (along with "flexibility", "fair competition among EU industries", "fairness", "subsidiarity", and "competitiveness", see Lacasta et al., 2010, for an analysis of the decision). The agreed targets have resulted from compromises between these principles, as well as from various political considerations that arose during the negotiations. Therefore, it is likely that the BSA targets alone will not readily permit to achieve cost-effectiveness (Tol, 2009). How large the costs associated to the BSA targets will be in comparison with that of the cost-effective solution remains, however, an open question.

While the implementation of the ETS has given rise to many economic studies (Böhringer et al., 2006; Ellerman \& Buchner, 2008; Böhringer et al., 2009; Convery, 2009), the sectoral implications of the BSA for non-ETS emissions have received less attention so far. Capros et al. (2008) and HöglundIsaksson et al. (2010) provide quantitative assessments of the non-ETS objectives, which have been used by the European Commission in the preparatory phase of the BSA. Tol (2009) examines the impacts of various settings of flexibility mechanisms for the non-ETS sector as a whole. The present 
article focuses on emissions from the agricultural sector and sheds some quantitative light on what is at stake for this sector.

The assessment of marginal abatement costs (MAC) is key to the issue of cost-effectiveness. In the environmental economics literature, empirical and analytical approaches differ in this respect. In studies falling in the latter category, MAC curves are commonly specified as linear functions, which are easy to manipulate analytically (see for instance Newell \& Stavins, 2003; Tol, 2009). By contrast, the applied economic studies that have estimated empirical MAC curves for agricultural emissions usually underline the non-linearities that prevail in their results. Moreover, linear specifications require in general additional conditions on the level of abatement to hold for some basic properties of the abatement supply to be fulfilled, e.g. that abatement does not exceed emissions. In this article, we propose an alternative, non-linear specification for MAC curves. This specification has several advantages. First, it summarizes any MAC curve with a few (three) parameters that can easily be estimated and interpreted. Second, it readily ensures that emission reductions do not exceed initial emissions without requiring additional restrictions on the value of abatement. Third, as we illustrate in this paper, the functional form fits fairly well the empirical MAC curves obtained from an applied economic model that accounts for the heterogeneities in abatement potential and costs. Last, the fitted MAC curves can be used as reduced forms to quantify the implications of a wide range of mitigation policies without the burden of having to run multiple simulations of a large-scale model.

The present paper provides an illustration of how such a specification can be used in an applied economic work. We estimate the parameters defining the MAC curve for each Member State's agricultural emissions. In the literature, empirical MAC curves have been derived from various models, including technical-economic supply-side models (De Cara et al., 2005; Hediger, 2006), bottom-up engineering assessments of the costs and potential of abatement technologies (Beach et al., 2008; Moran et al., 2010; Höglund-Isaksson et al., 2010), and partial or general equilibrium models (McCarl \& Schneider, 2001; Schneider et al., 2007; Pérez Domínguez et al., 2009; Golub et al., 2009). These assessments considerably vary in scope (sources of emissions, gases, and mitigation options considered), modelling assumptions, and geographic scale and resolution. See Vermont \& De Cara (2010) for a recent quantitative survey. Our estimations are based on the outputs of an updated version of the model of the European agricultural supply presented in De Cara et al. (2005). The obtained reduced forms are then used to compute the cost-effective burden sharing across Member States, the corresponding emission price, total abatement costs, as well as the cost-savings permitted by market-based instruments.

The remainder of the paper is organized as follows. Section 2 presents some facts about the EU 
BSA and the distribution of non-ETS emissions. The notations are introduced and the properties of the MAC specification proposed in this paper are discussed in Section 3. The empirical model is presented in Section 4. Section 5 presents the fitted country-specific MAC curves. The results in terms of cost-effective burden sharing, equilibrium emission price, and total abatement costs are detailed in Section 6. A sensitivity analysis is carried out in Section 7. Section 8 concludes.

\section{Emissions from agriculture and the EU non-ETS Burden Sharing Agreement}

Meeting the EU objective of a 20\% reduction of GHG emissions by 2020 compared to 1990 levels (30\% if an international agreement is reached) should not rely solely on reductions in the energyintensive sectors currently covered by the ETS. The decision 406/2009/EC (European Union, 2009) stresses the importance of sharing the mitigation burden among all emitting sectors, and aims at broadening the scope of the EU climate policy to emissions from other sectors.

The wide diversity across Member States in terms of per-capita GDP and expected growth involves large differences among Member States in terms of (total and per-capita) GHG emissions, decomposition by gas, sector, and sources (European Environment Agency, 2010a). Table 1 illustrates this diversity for non-ETS and agricultural emissions. In 2005, agricultural emissions account for more than one sixth of total non-ETS emissions. The share of agriculture in non-ETS emissions varies from $6.7 \%$ (Luxembourg) to $43 \%$ (Ireland). It is slightly higher on average in the New Member States (19\%) than in the rest of the EU. Four countries (France, Germany, United Kingdom, and Spain) account for more than half of total European agricultural emissions. Agricultural emissions in the New Member States represent slightly less than $20 \%$ of total EU agricultural emissions, the largest emitting countries in this group being Poland, Romania, Hungary, and the Czech Republic.

The variety of the countries' situations with respect to non-ETS emissions has led the EU to adopt a set of differentiated targets to comply with its overall abatement objective. The EU decision regarding the BSA explicitly refers to the differences in (current and expected) per-capita GDP among Member States as the main justification of setting less stringent targets for the Member States characterized by lower per-capita GDP (preamble, paragraph 8).

The agreed abatement targets for non-ETS emissions are reported in Table 1. They range from $-20 \%$ to $20 \%$. A negative abatement target indicates that the corresponding Member State may increase its non-ETS emissions between 2005 and 2020. All New Member States but Cyprus fall in this category, with allowed increases in emissions ranging from 4\% (Slovenia) to 20\% (Bulgaria). By contrast, all EU-15 countries but Portugal are assigned a reduction target. Three Member States (Denmark, Ireland, and Luxembourg) are assigned the highest reduction target (20\%). Interestingly, 
Table 1: Data: Member-State non-ETS and agricultural emissions.

\begin{tabular}{|c|c|c|c|c|c|}
\hline \multirow[b]{2}{*}{ Member State (MS) } & \multicolumn{3}{|c|}{2005 emissions } & \multirow[b]{2}{*}{$\begin{array}{l}\text { Non-ETS aba- } \\
\text {-tement target }^{(c)} \\
(\%, 2020 / 2005)\end{array}$} & \multirow[b]{2}{*}{$\begin{array}{c}\text { Expected change in } \\
\text { BAU ag. emissions }{ }^{(d)} \\
(\%, 2020 / 2005)\end{array}$} \\
\hline & $\begin{array}{l}\text { Non-ETS } \\
\text { emissions }^{(a)} \\
\left(\mathrm{MtCO}_{2} \mathrm{eq}\right)\end{array}$ & $\begin{array}{l}\text { Agricultural } \\
\text { emissions }^{(b)} \\
\left(\mathrm{MtCO}_{2} \mathrm{eq}\right)\end{array}$ & $\begin{array}{l}\text { Share of ag. emis- } \\
\text {-sions in non ETS } \\
(\%)\end{array}$ & & \\
\hline Austria (AT) & 58.9 & 7.9 & 13.5 & 16.0 & -1.9 \\
\hline Belgium (BE) & 85.3 & 10.5 & 12.3 & 15.0 & 0.9 \\
\hline Germany (DE) & 494.6 & 68.6 & 13.9 & 14.0 & -5.7 \\
\hline Denmark (DK) & 37.3 & 10.4 & 27.8 & 20.0 & -2.6 \\
\hline Spain (ES) & 251.7 & 43.4 & 17.2 & 10.0 & 6.9 \\
\hline Finland (FI) & 35.0 & 6.0 & 17.0 & 16.0 & -7.5 \\
\hline France (FR) & 418.3 & 103.0 & 24.6 & 14.0 & -3.0 \\
\hline Greece (GR) & 59.1 & 9.9 & 16.7 & 4.0 & -4.1 \\
\hline Ireland (IE) & 47.8 & 20.6 & 43.0 & 20.0 & -2.9 \\
\hline Italy (IT) & 346.5 & 39.3 & 11.3 & 13.0 & -0.4 \\
\hline Luxembourg (LU) & 10.7 & 0.7 & 6.7 & 20.0 & -6.6 \\
\hline Netherlands (NL) & 132.6 & 19.8 & 14.9 & 16.0 & 1.5 \\
\hline Portugal (PT) & 51.6 & 8.7 & 16.9 & -1.0 & 0.1 \\
\hline Sweden (SE) & 47.9 & 9.1 & 19.0 & 17.0 & -5.4 \\
\hline United Kingdom (UK) & 408.8 & 49.1 & 12.0 & 16.0 & -4.2 \\
\hline EU15 & 2486.0 & 406.9 & 16.4 & 13.9 & -2.0 \\
\hline Cyprus (CY) & 4.6 & 0.8 & 18.3 & 5.0 & 5.5 \\
\hline Czech Republic (CZ) & 64.1 & 8.4 & 13.1 & -9.0 & -5.8 \\
\hline Estonia (EE) & 7.0 & 1.3 & 19.3 & -11.0 & -11.6 \\
\hline Hungary (HU) & 54.1 & 9.1 & 16.9 & -10.0 & -2.8 \\
\hline Lithuania (LT) & 16.8 & 5.2 & 31.1 & -15.0 & -8.6 \\
\hline Latvia (LV) & 8.8 & 2.1 & 24.0 & -17.0 & -3.5 \\
\hline Poland (PL) & 189.5 & 36.1 & 19.1 & -14.0 & 3.1 \\
\hline Slovenia (SI) & 11.6 & 2.2 & 18.7 & -4.0 & -6.6 \\
\hline Slovakia (SK) & 25.4 & 3.4 & 13.3 & -13.0 & -8.1 \\
\hline Bulgaria (BG) & 34.1 & 5.3 & 15.6 & -20.0 & -5.0 \\
\hline Malta (MT) & 0.9 & 0.1 & 10.4 & -5.0 & -22.5 \\
\hline Romania (RO) & 89.2 & 21.9 & 24.6 & -19.0 & -2.4 \\
\hline New MS (NMS) & 506.1 & 96.1 & 19.0 & -14.3 & -1.5 \\
\hline EU27 & 2992.0 & 503.0 & 16.8 & 9.1 & -1.9 \\
\hline
\end{tabular}

(a) Total 2005 emissions (excluding LULUCF) of $\mathrm{CO}_{2}, \mathrm{CH}_{4}(\mathrm{GWP}=25)$, and $\mathrm{N}_{2} \mathrm{O}(\mathrm{GWP}=298$ ) minus 2005 ETS verified emissions (2008 for Bulgaria and Romania), source: EEA, 2010b. ${ }^{(b)}$ Total emissions of $\mathrm{CH}_{4}(\mathrm{GWP}=25)$ and $\mathrm{N}_{2} \mathrm{O}(\mathrm{GWP}=298)$ from agriculture, source: EEA, 2010b. ${ }^{(c)}$ Source: EU, 2009. ${ }^{(d)}$ Relative change in agricultural emissions of $\mathrm{CH}_{4}(\mathrm{GWP}=25)$ and $\mathrm{N}_{2} \mathrm{O}(\mathrm{GWP}=298)$ from the GAINS model for a zero emission price. Source: IIASA, 2010. 
two of these countries-Denmark and Ireland-are also characterized by the highest share of agricultural emissions in non-ETS emissions among EU-15 countries (about 28\% and 43\%, respectively). The application of the BSA targets to the non-ETS emissions as computed in Table 1 leads to a 9.1\% reduction ${ }^{1}$ for the EU27. It corresponds to a $13.9 \%$ reduction for the EU-15 (83\% of the EU non-ETS emissions), partially offset by a $14.3 \%$ increase in the New Member States.

As the targets are expressed for 2020 emissions relative to 2005 levels, the expected evolution of business-as-usual (BAU) emissions between 2005 and 2020 will influence the actual effort implied by the BSA. The last column of Table 1 provides an indication of the expected change in agricultural emissions of each Member State based on the baseline figures from the GAINS model (IIASA, 2010; Höglund-Isaksson et al., 2010), the results from which were used by the European Commission as background material during the preparation of the BSA decision. According to this model, agricultural BAU emissions are expected to decrease in a majority of European countries with the exception of Belgium, Spain, Netherlands, Portugal, Cyprus, and Poland. The rate of change in agricultural BAU emissions between 2005 and 2020 ranges from $-22.5 \%$ (Malta) to $+6.9 \%$ (Spain). The implied relative change for the whole EU amounts to $-1.9 \%$, with a slightly more pronounced decrease in EU-15 (-2\%) countries than in New Member States (-1.5\%). This suggests that the overall reduction in non-ETS emissions (relative to 2005 levels) may be partially achieved thanks to exogenous changes in the economic, policy, and technical drivers of emissions.

Cost-effectiveness implies that MAC are equalized across countries and across sectors. Given the heterogeneity of abatement costs and potentials, one may expect the cost-effective abatement effort to considerably vary from one country or sector to the other. Nothing ensures that the BSA targetswhich are largely based on relative per-capita GDP-will readily correspond to a cost-effective effort sharing. Meeting the EU target in a cost-effective manner will thus require flexibility mechanisms across countries and sectors. Although cost-effectiveness is put forth as one key principle in the EU BSA, it is not yet clear how it could be articulated with the subsidiarity principle and whether the provisions regarding flexibility mechanisms would permit to achieve full cost-effectiveness (Tol, 2009).

\section{Abatement supply and abatement costs}

In this section, we introduce the notations and computations used in the empirical application. We denote by $E_{0 i}$ the base-year agricultural GHG emissions (in $\mathrm{MtCO}_{2} \mathrm{eq}$ ) in country $i(i=1, \ldots, n)$.

\footnotetext{
${ }^{1}$ The difference with the EU stated objective of an overall $10 \%$ reduction in non-ETS emissions may be explained by the use of more recent inventory data and updated GWP values for methane and nitrous oxide (25 and 298, respectively).
} 
When an emission price $p$ (in $€ / \mathrm{tCO}_{2} \mathrm{eq}$ ) is introduced, farmers respond by adjusting their production choices. The corresponding base-year emissions for country $i$ are denoted by $E_{i}(p)$, with $E_{i}(p) \leq E_{0 i}$. For the ease of inter-country comparison, it will be useful to normalize emission reductions and use the abatement rate defined as:

$$
\alpha_{i}(p)=1-\frac{E_{i}(p)}{E_{0 i}}
$$

We posit the following specification for the abatement supply:

$$
\alpha_{i}(p)=\bar{\alpha}_{i}\left(1-e^{-\left(\frac{p}{\tau_{i}}\right)^{\beta_{i}}}\right)
$$

Under the assumptions that $0<\bar{\alpha}_{i} \leq 1, \beta_{i}>0$ and $\tau_{i}>0$, equation (2) ensures that the abatement supply ${ }^{2}$ is positive and increasing with respect to $p$. If $\beta_{i}>1$, the abatement supply function has an inflexion point at $p=\tau_{i}\left(\frac{\beta_{i}-1}{\beta_{i}}\right)^{\frac{1}{\beta_{i}}}$. When the emission price tends to infinity, the abatement rate in country $i$ tends to $\bar{\alpha}_{i}$. Therefore, $\bar{\alpha}_{i} E_{0 i}$ represents the maximum technically feasible abatement, which is possibly lower than base emissions, and $\left(1-\bar{\alpha}_{i}\right) E_{0 i}$ represents the amount of incompressible emissions. An essential feature of specification (2) is that it readily ensures that "one cannot abate more than one emits" (provided that $\bar{\alpha}_{i} \leq 1$ ). Formulations that are generally used in the literaturebe they linear (for instance, Newell \& Stavins, 2003), log-linear (Vermont \& De Cara, 2010), or polynomial (Böhringer et al., 2006)-require additional restrictions on the level of abatement for this to hold.

The responsiveness of the abatement supply can be (locally) characterized by the relative change in the abatement rate due to a $1 \%$ change in the emission price. Using specification (2), the price elasticity of the abatement rate $\left(\mu_{i}=\frac{d \alpha_{i}}{\alpha_{i}} / \frac{d p}{p}\right)$ is:

$$
\mu_{i}(p)=\frac{\beta_{i}\left(\frac{p}{\tau_{i}}\right)^{\beta_{i}}}{e^{\left(\frac{p}{\tau_{i}}\right)^{\beta_{i}}}-1}
$$

Equation (3) indicates that $\mu_{i}$ depends only on $\beta_{i}$ and $\frac{p}{\tau_{i}}$ and is decreasing with respect to $\frac{p}{\tau_{i}}$. For the range of values we shall explore in sections 5 and $6, \mu_{i}(p)$ is increasing with respect to $\beta_{i}$. Another indicator of the price response of $\alpha_{i}(p)$-which may be easier to interpret-is the price elasticity of emissions $\left(\eta_{i}=\frac{d E_{i}}{E_{i}} / \frac{d p}{p}\right)$. Using equation (1), it can be easily shown that:

$$
\eta_{i}(p)=-\mu_{i}(p) \frac{\alpha_{i}(p)}{1-\alpha_{i}(p)}
$$

The MAC curve (as a function of the abatement rate) is obtained by inverting (2):

$$
C_{i}^{m}(\alpha)=\tau_{i}\left(\ln \frac{\bar{\alpha}_{i}}{\bar{\alpha}_{i}-\alpha}\right)^{\frac{1}{\beta_{i}}}
$$

\footnotetext{
${ }^{2}$ Note that when $\bar{\alpha}_{i}=1$, equation (2) is similar to the definition of the cumulative distribution function of a Weibull distribution with shape and scale parameters equal to $\beta_{i}$ and $\tau_{i}$, respectively.
} 
As $\alpha$ approaches the maximum abatement rate $\bar{\alpha}_{i}$, the marginal abatement cost tends to infinity. The role of $\tau_{i}$ as a scaling factor is apparent in equation (5). Holding all other parameters constant, a greater value of $\tau_{i}$ implies a higher MAC for the same abatement rate.

Assuming that fixed costs of abatement are zero, total abatement costs (in $\mathrm{M} €$ ) for country $i$ and any abatement rate $0 \leq \alpha<\bar{\alpha}_{i}$ are:

$$
C_{i}(\alpha)=E_{0 i} \int_{0}^{\alpha} C_{i}^{m}(u) d u
$$

Using equation (5) and a simple change of variable, total abatement costs can be expressed as a function of the parameters defining the abatement supply function:

$$
C_{i}(\alpha)=\tau_{i} \bar{\alpha}_{i} E_{0 i} \gamma\left(1+\frac{1}{\beta_{i}}, \ln \frac{\bar{\alpha}_{i}}{\bar{\alpha}_{i}-\alpha}\right)
$$

where $\gamma(x, z)$ is the (lower) incomplete Gamma function defined as:

$$
\gamma(x, z)=\int_{0}^{z} v^{x-1} e^{-u} d u
$$

Although equation (7) does not provide a closed form for total abatement costs when $\beta \neq 1$, numerical computations can be easily performed using standard statistical softwares provided that the values of $E_{0 i}, \bar{\alpha}_{i}, \beta_{i}$, and $\tau_{i}$ are known.

For any given abatement target $\tilde{\alpha}$, the cost-effective vector of country abatement rates $\left(\alpha_{1}^{*}, \ldots, \alpha_{n}^{*}\right)$ is characterized by

$$
C_{i}^{m}\left(\alpha_{i}^{*}\right)=C_{j}^{m}\left(\alpha_{j}^{*}\right) \text { for all } i, j=1, \ldots, n, i \neq j \text { and } \sum_{k=1}^{n} \alpha_{k}^{*} E_{0 k}=\tilde{\alpha} \sum_{k=1}^{n} E_{0 k}
$$

Given the non-linearity of (5), getting an analytical solution ${ }^{3}$ of (9) is less straightforward than under a linear MAC specification. However, as will be illustrated in Section 6, it is possible in practice to get a convergent numerical solution of (9) by selecting well-chosen starting values for $\alpha_{i}^{*}$. The cost-effective abatement rates $\alpha_{i}^{*}$ and the corresponding MAC can thus be obtained numerically.

The equalization of MAC across countries corresponds to the outcome of a (well-functioning) emission trading system. It is then possible to assess the cost-savings permitted by market-based instruments. Consider that a burden sharing vector $\left(\tilde{\alpha}_{1}, \ldots, \tilde{\alpha}_{n}\right)$ such that $\sum_{k} \tilde{\alpha}_{k} E_{0 k}=\tilde{\alpha} \sum_{k} E_{0 k}$ has been agreed upon. Consider also that a cap-and-trade system is implemented with initial allowances defined by $\left(\tilde{\alpha}_{1}, \ldots, \tilde{\alpha}_{n}\right)$. In this case, country $i$ will have to buy (sell) permits if $\tilde{\alpha}_{i}>\alpha_{i}^{*}\left(\tilde{\alpha}_{i}<\alpha_{i}^{*}\right)$. The net amount paid by country $i$ when permits are traded at equilibrium price $p^{*}\left(p^{*}=C_{i}^{\prime}\left(\alpha_{i}^{*}\right)\right.$ for all $\left.i\right)$ is:

$$
T R_{i}\left(\alpha_{i}^{*}, \tilde{\alpha}_{i}\right)=p^{*}\left(\tilde{\alpha}_{i}-\alpha_{i}^{*}\right) E_{0 i}
$$

\footnotetext{
${ }^{3}$ Existence of a solution to (9) for $0 \leq \tilde{\alpha}<\min _{i} \bar{\alpha}_{i}$ is ensured by the continuity of $C_{i}^{\prime}()$ and the assumption that $C_{i}^{\prime}(0)=0$ for all $i$. The monotonicity of $C_{i}^{\prime}()$ for all $i$ implies that the solution, when it exits, is unique.
} 
The net gain from trade for country $i$ is thus:

$$
N G_{i}\left(\alpha_{i}^{*}, \tilde{\alpha}_{i}\right)=C_{i}\left(\tilde{\alpha}_{i}\right)-C_{i}\left(\alpha_{i}^{*}\right)-T R_{i}\left(\alpha_{i}^{*}, \tilde{\alpha}_{i}\right)
$$

In absence of transaction costs, the net gain from trade is-by construction-unambiguously non-negative for all $i$. As the net transfers sum to zero, the sum of net gains across countries reduces to the total savings in abatement costs, ie $\sum_{k}\left(C_{k}\left(\tilde{\alpha}_{k}\right)-C_{k}\left(\alpha_{k}^{*}\right)\right)$.

Equation (2) is defined for an instantaneous reduction in base-year $(t=0)$ emissions. The framework presented above can easily be extended to the case of a reduction commitment at a future date and changing-over-time BAU emissions. Consider that the abatement target applies to the emissions at some future date $t=T$ relative to base-year emissions $E_{0 i}$. We denote by $\hat{E}_{T i}$ the BAU emissions at date $T$, which may be smaller or greater than $E_{0 i}$ due to changes in some exogenous drivers. We denote by $\hat{\lambda}_{i}$ the expected reduction rate in BAU emissions between $t=0$ and $t=T$, so that:

$$
\hat{E}_{T i}=\left(1-\hat{\lambda}_{i}\right) E_{0 i}
$$

We assume that the only impact of the exogenous changes in emissions is to shift the supply curve (expressed in relative terms) upward or downward such that $\hat{\alpha}_{i}(0)=\hat{\lambda}_{i}$. The modified abatement supply is thus:

$$
\hat{\alpha}_{i}(p)=\bar{\alpha}_{i}\left(1-e^{-\left(\frac{p}{\tau_{i}}\right)^{\beta_{i}}}\right)+\hat{\lambda}_{i},
$$

which leads to the corresponding (modified) MAC curve:

$$
\hat{C}_{i}^{m}(\alpha)= \begin{cases}\tau_{i}\left(\ln \frac{\bar{\alpha}_{i}}{\bar{\alpha}_{i}+\hat{\lambda}_{i}-\alpha}\right)^{\frac{1}{\beta_{i}}} & \text { if } \hat{\lambda}_{i}<\alpha<\bar{\alpha}_{i} \\ 0 & \text { if } \alpha \leq \hat{\lambda}_{i}\end{cases}
$$

The (modified) total abatement costs are obtained by integrating (14):

$$
\hat{C}_{i}(\alpha)= \begin{cases}\tau_{i} \bar{\alpha}_{i} E_{0 i} \gamma\left(1+\frac{1}{\beta_{i}}, \ln \frac{\bar{\alpha}_{i}}{\bar{\alpha}_{i}+\hat{\lambda}_{i}-\alpha}\right) & \text { if } \hat{\lambda}_{i}<\alpha<\bar{\alpha}_{i} \\ 0 & \text { if } \alpha \leq \hat{\lambda}_{i}\end{cases}
$$

The second case in (15) corresponds to the presence of 'hot air' in the sense that the expected decrease in BAU emissions alone is sufficient to meet the abatement target. The first case corresponds to a real abatement effort as $\alpha \geq \hat{\lambda}_{i}$. If country $i$ 's BAU emissions are expected to decrease $\left(\hat{\lambda}_{i}>0\right)$, only the abatement beyond $\hat{\lambda}_{i}$ entails abatement costs. In other words, $\hat{\lambda}_{i} E_{0 i}$ represents the amount of 'free' abatement for country $i$. In case of increasing BAU emissions $\left(\hat{\lambda}_{i}<0\right)$, the abatement effort must more than offset the extra burden due to the expected increase in BAU emissions.

The exogenous changes in BAU emissions have an impact on equilibrium quantities and prices, as well as on the distribution of transfers and net gains of trade across countries. Holding all other 
parameters constant, countries that are characterized by a decrease in BAU emissions $\left(\hat{\lambda}_{i}>0\right)$ can sell more permits on the market at no additional cost. On the contrary, countries characterized by $\hat{\lambda}_{i}<0$ have to buy more permits to offset the increase in their BAU emissions.

\section{The model}

The simulations rely on an updated version of the model presented in De Cara et al. (2005). Changes from that version most notably include a revised typology of European farms, an expanded crop coverage that now includes cotton, flax, and tobacco, and the use of more recent accountancy data from the EU Farm Accounting Data Network database (FADN 2004). This database provides economic, structural, and technical data about farmers in 24 EU Member States (MS) ${ }^{4}$. For a technical description of the model's structure and main features, see De Cara et al. (2005).

The model consists of a set of 1,307 independent, mixed integer linear-programming models. Each model describes the economic behavior of a representative farmer (or farm-type) with respect to crop area allocation, animal numbers, and animal feeding. It covers the main annual crops and animal categories relevant for European agriculture. Resource allocation is based on gross margin maximization subject to technical and policy constraints for given values of the exogenous parameters describing the technical, economic, and policy environment (yields, input and output prices, subsidies, total agricultural area, quotas, etc.).

The 'farm types' are representative of the agricultural sector at the regional level. 119 regions are represented in the model. The main interest of a bottom-up approach based on farm-types is to capture the wide diversity of technical and policy constraints faced by European farmers. The set of constraints include: (i) crop and grassland area availability (subject to rotation constraints summarized in maximal area shares); (ii) CAP-related constraints; (iii) constraints reflecting the demographic equilibrium in the distribution of age and sex classes of cattle numbers; (iv) animal feeding constraints (energy/protein requirements and maximal quantity of ingested matter for each animal category); (v) constraints on animal numbers, which are only allowed to deviate from the initial livestock numbers within a given range. The latter set of constraints is defined at the farm-type level for each animal category (cattle, sheep, goats, swine, poultry). It is meant to reflect the inertia in the adjustment of livestock numbers. Following De Cara et al. (2005), we assume in our central set of simulations that livestock numbers are allowed to vary within $\pm 15 \%$ of the values reported in the FADN database $(\delta=0.15)$. As it defines the admissible ranges of livestock numbers in each animal category, this

\footnotetext{
${ }^{4}$ No data were available for Malta in the EU-FADN database for 2004. Bulgaria and Romania, which were not Member States in 2004 are excluded.
} 
choice is likely to influence the value of $\bar{\alpha}_{i}$ (for a discussion, see De Cara et al., 2005). In Section 7 , we shall conduct sensitivity analyses of the results with two alternative values of $\delta$.

The emission coverage includes the main sources of non- $\mathrm{CO}_{2}$ GHG emissions directly caused by agricultural activities: methane $\left(\mathrm{CH}_{4}\right)$ emissions from enteric fermentation, manure management, and rice cultivation; nitrous oxide $\left(\mathrm{N}_{2} \mathrm{O}\right)$ emissions from agricultural soil and manure management. Emission accounting methods and the choice of emission factors are consistent with the informationwhenever available-contained in the individual Member States' GHG inventories. When this information is lacking, the IPCC guidelines and default factors are used (Eggleston et al., 2006). Emissions of $\mathrm{CH}_{4}$ and $\mathrm{N}_{2} \mathrm{O}$ are aggregated into $\mathrm{CO}_{2}$ eq using the 2007 Global Warming Potential $\left(\mathrm{GWP}_{\mathrm{N}_{2} \mathrm{O}}=298\right.$, $\left.\mathrm{GWP}_{\mathrm{CH}_{4}}=25\right)$.

The model is calibrated against 2004 FADN data. As the reference year for the BSA targets is 2005, we first introduce the changes in the policy environment that occurred in 2005, most notably the changes in subsidies and CAP provision and the introduction of the decoupling schemes implied by the 2003 CAP reform (Debove \& Jayet, 2007). This provides us with the reference year situation with regard to agricultural area allocation among the various crops represented in the model, animal numbers, animal feeding composition, output, gross margin, and GHG emissions. Computed total emissions for the year 2005 are $394.5 \mathrm{MtCO}_{2}$ eq. This figure is to be compared to $475.7 \mathrm{MtCO}_{2}$ eq of agricultural emissions reported by the European Environment Agency (2010a, using the same GWP values) in the year 2005 for the 24 Member States represented in the model. The model thus represents about $83 \%$ of the reported emissions. Computed emissions for each Member State are given in Table 3 (second column).

An emission price $p$ is then introduced in each individual model. Seventy values of $p$ are explored, varying from 0 to $10,000 € / \mathrm{tCO}_{2}$ eq by steps of increasing size. ${ }^{5}$ For each value of the emission price, marginal abatement costs are equalized among farm-types by construction. The cost-effective abatement rate can thus be computed for each value of $p$ at various levels of aggregation (farm, region, Member State, EU). It is important to keep in mind that the abatement obtained at price $p$ is contingent to the chosen values of the exogenous parameters (input and output prices, yields, total agricultural area, number and geographic distribution of farm types), which are held constant in the simulations. As discussed in De Cara et al. (2005), this assumption is rather conservative with regard to the abatement potential that can be achieved at a given emission price.

\footnotetext{
${ }^{5}$ Such a high value for the upper limit of the price range might be surprising as it is several orders of magnitude larger than the commonly considered $\mathrm{CO}_{2}$ prices. It thus has little policy relevance per se, but is useful for numerical purposes as it allows to mimic the asymptotic behavior of the model as $p$ goes to infinity, and thus obtain a robust estimation of $\bar{\alpha}_{i}$.
} 


\section{Marginal abatement cost functions}

The functional form (2) is then fitted using the levels of the emission price and the corresponding simulated values of the abatement rate aggregated at the Member State, EU-15, New Member State, and EU-wide levels. The results of the non-linear fit are presented in Table $3 .^{6}$

We first focus on the EU-aggregated results. The simulated abatement supply (dots) and fitted values (solid line) for the EU are presented in Figure 1.a for the full range of emission prices. The maximum abatement rate is estimated to be approximately $60 \%$ of the base emissions. The estimated parameters imply that approximately a third of this potential abatement is exhausted at a price of $100 € / \mathrm{tCO}_{2}$ eq. The abatement supply function does not have an inflexion point, as $\beta<1$. Based on the estimated parameters, the emission price that corresponds to a $10 \%$ reduction in EU base emissions is about $41.1 € / \mathrm{tCO}_{2}$ eq. At this price, the implied price elasticity of the abatement rate is approximately $\mu=0.7$. This corresponds to a price elasticity of emissions $\eta=-0.076$. These figures can be compared with the results of the meta-analysis by Vermont \& De Cara (2010), who estimated $\mu$ and $\eta$ (for the same abatement rate) to be approximately 0.6 and -0.066 , respectively.

The estimation results also indicate that the maximum abatement rate is higher in the New Member States as a whole than in the EU-15 (about 66\% and 59\%, respectively). At the Member State level, estimated values of $\bar{\alpha}_{i}$ in the EU-15 range from $43 \%$ (the Netherlands) to $67 \%$ (France), whereas they range from 54\% (Cyprus) to 74\% (Lithuania) in the New Member States. The estimated abatement supply shows an inflexion point $\left(\beta_{i}>1\right)$ in nine Member States.

How does the implied MAC curve compare with existing estimates in the literature? Figure 1.b presents the implied MAC curve for the EU over a narrower price range (up to $100 € / \mathrm{tCO}_{2} \mathrm{eq}$ ), along with the MAC curve derived from Vermont \& De Cara's meta-analysis (dashed) and the corresponding 1 -standard error confidence interval ${ }^{7}$. For abatement rates above $5 \%$, the MAC curve found in the present paper is lower than that derived from the meta-analysis by Vermont \& De Cara. It remains nevertheless within 1 s.e of the central estimate of Vermont \& De Cara. This may be partially explained by lower abatement costs in the New Member States, which were seldom included in previous analyses in the literature.

${ }^{6}$ The MAC curves are fitted with R 2.11.1 using the non-linear least squares function provided in package stats.

${ }^{7}$ The confidence interval is reconstructed from the log-log abatement supply function estimated by Vermont \& De Cara (Table 4, Model 6, standard error: 0.5624) taking all explanatory variables used by these authors at their mean values except the spatial dummies (EU set to 1, USA and ROW set to 0). 
Table 2: Results of the non-linear fit of the abatement supply function $\alpha_{i}(p)=\bar{\alpha}_{i}\left(1-e^{\left(-\frac{p}{\tau_{i}}\right)^{\beta_{i}}}\right)$ at various levels of aggregation (animal number adjustment factor: $\delta=0.15$ ). Degrees of freedom=67.

\begin{tabular}{|c|c|c|c|c|c|c|c|c|}
\hline \multirow[b]{2}{*}{ MS } & \multirow[b]{2}{*}{$\begin{array}{c}E_{0 i} \\
\left(\mathrm{MtCO}_{2} \mathrm{eq}\right)\end{array}$} & \multicolumn{2}{|c|}{$\bar{\alpha}_{i}$} & \multicolumn{2}{|c|}{$\beta_{i}$} & \multicolumn{2}{|c|}{$\tau_{i}$} & \multirow[b]{2}{*}{$\begin{array}{c}\hat{\sigma} \\
(1)\end{array}$} \\
\hline & & \multicolumn{2}{|c|}{ (1) } & (1) & $\mathrm{sd}$ & \multicolumn{2}{|c|}{$\left(€ / \mathrm{tCO}_{2} \mathrm{eq}\right)$} & \\
\hline AT & 5.8 & 0.536 & 0.004 & 0.804 & 0.015 & 296.2 & 7.8 & 0.012 \\
\hline $\mathrm{BE}$ & 10.8 & 0.498 & 0.006 & 0.785 & 0.028 & 165.7 & 6.9 & 0.021 \\
\hline $\mathrm{DE}$ & 56.8 & 0.577 & 0.002 & 0.905 & 0.010 & 331.4 & 4.7 & 0.008 \\
\hline DK & 8.8 & 0.511 & 0.003 & 1.107 & 0.015 & 464.9 & 7.3 & 0.008 \\
\hline ES & 28.0 & 0.566 & 0.005 & 0.912 & 0.022 & 286.7 & 8.2 & 0.016 \\
\hline FI & 4.4 & 0.646 & 0.004 & 1.247 & 0.027 & 241.6 & 4.3 & 0.016 \\
\hline FR & 90.7 & 0.667 & 0.003 & 0.834 & 0.011 & 257.9 & 4.1 & 0.010 \\
\hline GR & 11.8 & 0.491 & 0.004 & 0.967 & 0.020 & 301.0 & 7.1 & 0.012 \\
\hline IE & 14.8 & 0.597 & 0.003 & 1.204 & 0.020 & 201.9 & 2.7 & 0.012 \\
\hline IT & 39.1 & 0.628 & 0.003 & 0.801 & 0.011 & 292.1 & 5.3 & 0.010 \\
\hline LU & 0.5 & 0.566 & 0.005 & 0.684 & 0.018 & 201.0 & 7.4 & 0.017 \\
\hline NL & 13.0 & 0.434 & 0.009 & 0.807 & 0.041 & 396.9 & 30.3 & 0.026 \\
\hline PT & 6.6 & 0.466 & 0.003 & 0.949 & 0.021 & 119.4 & 2.4 & 0.012 \\
\hline SE & 6.8 & 0.572 & 0.003 & 0.945 & 0.016 & 254.8 & 4.8 & 0.011 \\
\hline UK & 39.3 & 0.551 & 0.004 & 1.307 & 0.037 & 201.7 & 4.2 & 0.018 \\
\hline EU15 & 337.3 & 0.589 & 0.002 & 0.893 & 0.008 & 268.7 & 2.8 & 0.006 \\
\hline CY & 1.0 & 0.536 & 0.007 & 1.005 & 0.038 & 303.0 & 12.7 & 0.024 \\
\hline $\mathrm{CZ}$ & 9.0 & 0.654 & 0.006 & 0.762 & 0.018 & 312.6 & 11.1 & 0.019 \\
\hline $\mathrm{EE}$ & 1.1 & 0.641 & 0.005 & 1.098 & 0.028 & 285.3 & 7.2 & 0.019 \\
\hline HU & 8.0 & 0.684 & 0.004 & 1.212 & 0.023 & 337.7 & 6.0 & 0.015 \\
\hline LT & 2.6 & 0.738 & 0.007 & 0.832 & 0.021 & 229.0 & 7.1 & 0.022 \\
\hline LV & 1.6 & 0.703 & 0.002 & 1.127 & 0.012 & 261.2 & 2.6 & 0.009 \\
\hline PL & 28.4 & 0.647 & 0.003 & 1.089 & 0.014 & 257.4 & 3.1 & 0.009 \\
\hline SI & 1.8 & 0.595 & 0.009 & 0.597 & 0.024 & 181.7 & 11.4 & 0.026 \\
\hline SK & 3.6 & 0.658 & 0.006 & 0.695 & 0.016 & 240.3 & 8.5 & 0.018 \\
\hline NMS & 57.2 & 0.656 & 0.003 & 0.966 & 0.011 & 276.0 & 3.5 & 0.009 \\
\hline EU & 394.5 & 0.599 & 0.002 & 0.903 & 0.007 & 270.1 & 2.4 & 0.005 \\
\hline
\end{tabular}




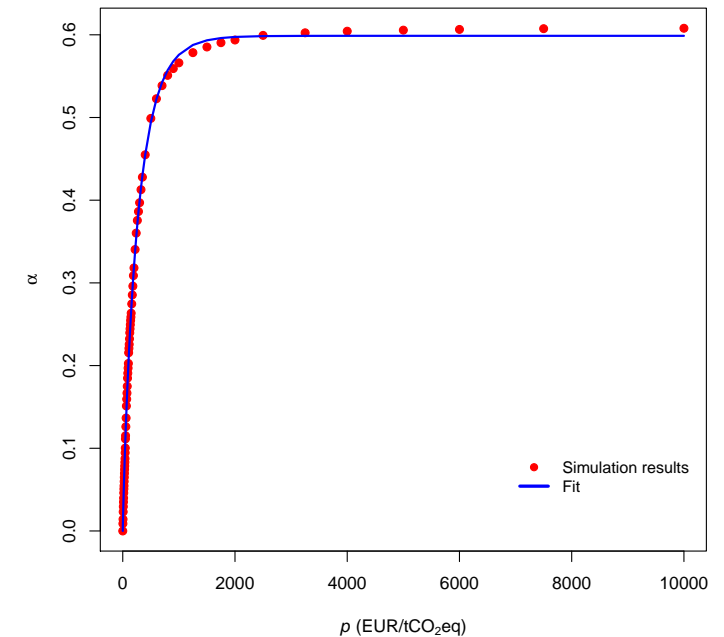

a. Abatement supply for the explored emission price range

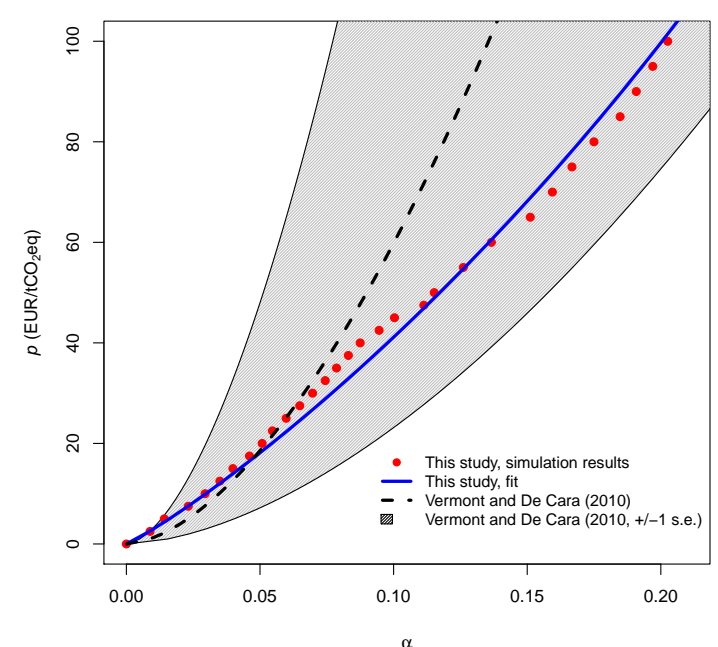

b. Implied MAC curve (emission price up to $\left.100 € / \mathrm{tCO}_{2} \mathrm{eq}\right)$

Figure 1: Simulation results (dots) and fitted values (solid line) for the EU abatement supply (left) and implied MAC curve (right).

\section{Cost-effective Burden Sharing}

Using the vector of abatement rates negotiated under the BSA agreement (Table 1, fifth column) and the estimated base-year emissions (Table 2, second column), the implied 2020 aggregate target corresponds to a $10.1 \%$ reduction in emissions compared to 2005 levels. We now turn to the costeffective solution that allows to reach the same abatement rate at the minimum total cost.

To numerically solve the non-linear system (9), we proceed in three steps. We first compute the emission price $p^{0}=C_{E U}^{m}(\tilde{\alpha})$ that corresponds to the aggregate target using the fitted MAC curve at the EU level and defined by the estimated parameter values reported in Table 2 (last row). Second, we compute the corresponding abatement rate for each country as $\alpha_{i}^{0}=\alpha_{i}\left(p^{0}\right)$ using equation (2) and the country-specific parameters reported in Table 2 . By construction, the resulting vector $\left(\alpha_{1}^{0}, \ldots, \alpha_{n}^{0}\right)$ satisfies the first $(n-1)$ equations of system (9) (equalization of MAC across countries), but does not satisfy in general the last equation of (9) because of the non linearity of the abatement supply. Nevertheless, it provides a close enough starting vector for the numerical solution to converge. The last step thus consists in numerically solving the full system (9) using $\left(\alpha_{1}^{0}, \ldots, \alpha_{n}^{0}\right)$ as starting values for $\left(\alpha_{1}^{*}, \ldots, \alpha_{n}^{*}\right)^{8}$

Figure 2 provides a comparison of the BSA targets ( $x$-axis) and the cost-effective abatement rates ( $y$-axis) in two situations. In Figure 2.a, the equilibrium is obtained assuming constant BAU emissions

\footnotetext{
${ }^{8}$ The non-linear system is solved within $\mathrm{R} 2.11 .1$ using the package nleqslv.
} 
and abatement costs between 2005 and 2020. In this case, the equilibrium price is $42.4 € / \mathrm{tCO}_{2} \mathrm{eq}$. In Figure 2.b, the changes in BAU emissions $\left(\hat{\lambda}_{i}\right)$ are set to match the values derived from the GAINS projections (Table 1, last column). In that case, the equilibrium emission price is lower $\left(32.2 € / \mathrm{tCO}_{2} \mathrm{eq}\right)$, as a consequence of the exogenous decrease in BAU emissions from EU agriculture predicted by GAINS. Note that, by construction, only the $y$-coordinates are different between Figure 2.a and Figure 2.b.

Figures 2 can be divided in four sectors. The countries represented above the horizontal line $\left(\alpha_{i}^{*} \geq \tilde{\alpha}=0.101\right)$ are characterized by a greater-than-average cost-effective abatement rate, thus signaling lower-than-average marginal abatement costs. Countries lying to the left of the 1:1 line are characterized by a greater cost-effective abatement rate than that prescribed by the BSA agreement. The further to the left (right) of the 1:1 line, the longer (shorter) will be the position of the corresponding country in a cap-and-trade system with initial allowances defined by the BSA targets.

As points in Figures 2 are fairly scattered throughout the plot, it appears clearly that the agreed BSA targets are far from readily ensuring cost-effectiveness, whatever the chosen assumption regarding the changes in BAU emissions. This underlines the importance of flexibility mechanisms. Although the cost-effective abatement rate of some Member State is affected by accounting for the change in BAU emissions (e.g. Spain, Cyprus, Poland, Estonia), the grouping in the four sectors described above is similar in Figures 2.a and 2.b. Even when accounting for the expected changes in BAU emissions, all New Member States but Cyprus should produce a mitigation effort greater than that prescribed by the BSA in the cost-effective situation. Conversely, all EU-15 Member States but Portugal, Greece, and-to a lesser extent-Luxembourg, are assigned targets that are higher than their respective cost-effective abatement rate.

Detailed results are presented in Table 3. Again, we distinguish between whether the changes in BAU emissions are accounted for (right) or not (left). The MAC corresponding to the BSA targets are reported in the columns labeled $\hat{C}_{i}^{m}\left(\tilde{\alpha}_{i}\right)$ and $C_{i}^{m}\left(\tilde{\alpha}_{i}\right)$, respectively. These figures may be interpreted as the emission tax that each country would have to set in order to fulfill its commitment in absence of flexibility among EU Member States. They range from 0 to more than $200 € / \mathrm{tCO}_{2}$ eq. All countries that have been assigned a negative BSA target are also characterized by $\tilde{\alpha}_{i} \leq \hat{\lambda}_{i}$. Marginal and total abatement costs to meet the BSA target are thus zero in these countries. The largest total abatement costs are faced by the largest emitters (France, Germany, the United Kingdom), but also by smaller emitters that have been assigned stringent targets (Denmark, The Netherlands, Ireland). Under the BSA and no flexibility, total abatement costs amount to almost 1,640 $\mathrm{M} €$ when changes in BAU emission are not accounted for, and about 1,220 M€ when they are. In both cases, the burden bears 


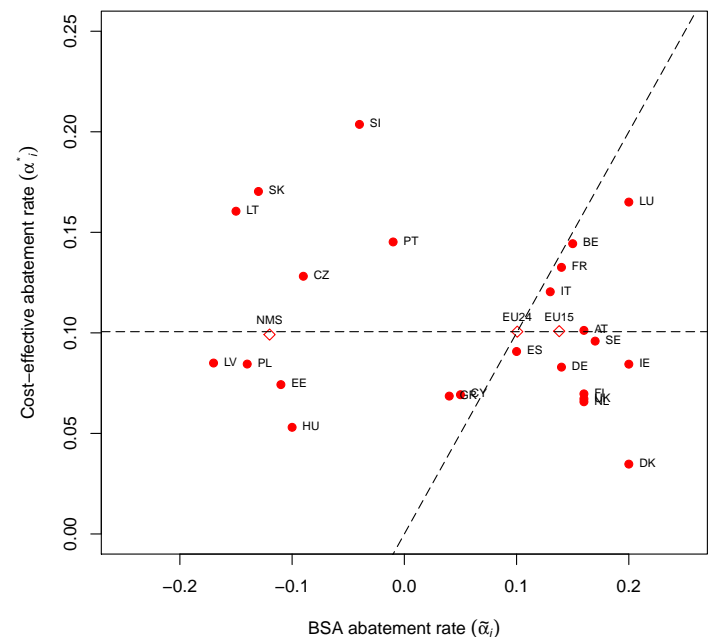

a. $\hat{E}_{2020, i}=E_{2005, i}$

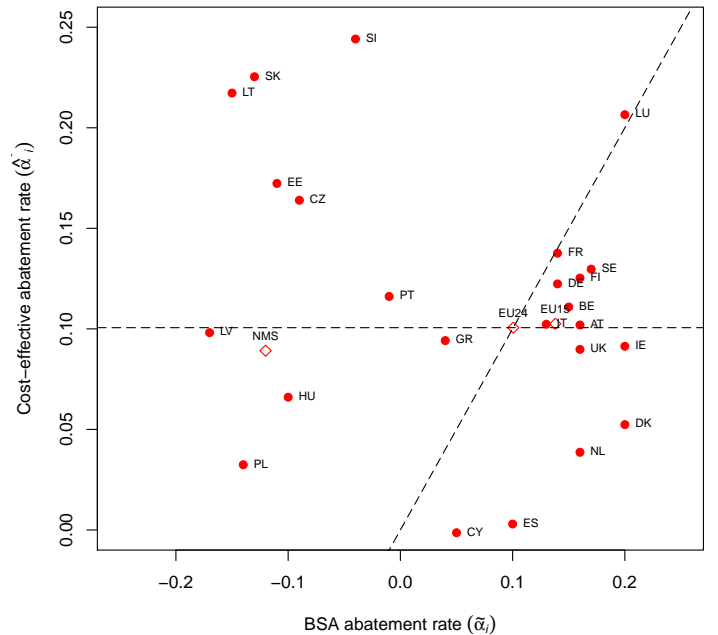

b. $\hat{E}_{2020, i}=\left(1-\hat{\lambda}_{i}\right) E_{2005, i}$

Figure 2: Cost-effective abatement rate (vertical axis) versus BSA targets (horizontal axis) for two assumptions regarding BAU emissions in $2020\left(\hat{E}_{2020, i}\right)$.

almost entirely on EU-15 countries.

The cost-effective abatement rate varies considerably from one country to the other, ranging from $-0.1 \%$ (Cyprus) to $24.4 \%$ (Slovenia) when accounting for the expected changes in BAU emissions. This again illustrates the diversity of MAC curves at the country level. The aggregated cost-effective abatement rates are of similar magnitude for the EU-15 as a whole (10.1\% if BAU emissions are constant until 2020, 10.3\% if not) and for the New Member States (9.9\% and 8.9\%) despite the significant differences that exist within these two groups. As for EU-15 countries, the total abatement costs associated with the cost-effective solution are two to three times lower than the respective abatement costs under the BSA and no flexibility. EU-wide cost savings are estimated to amount to about $870 \mathrm{M} €$ with constant BAU emissions, and about $750 \mathrm{M} €$ if the expected changes in BAU emissions are accounted for.

Should a cap-and-trade system be implemented and allowances be based on the BSA targets, it would imply transfers from EU-15 countries to the New Member States. All countries in the latter categories would be selling permits (except Cyprus if changes in BAU emissions are accounted for), while almost all EU-15 countries would be net buyers. Interestingly, the quantity of traded permits is fairly robust to the changes in BAU emissions. It would represent over a third of the overall abatement target (13.9 $\mathrm{MtCO}_{2}$ eq if BAU emissions are constant and $13.5 \mathrm{MtCO}_{2} \mathrm{eq}$ if not). The change in the total value of transfers between the two situations examined in Table 3 (588 and $436 \mathrm{M} €$, respectively) is thus mainly due to the change in the unit permit price in equilibrium (from 42.4 to $32.2 € / \mathrm{tCO}_{2} \mathrm{eq}$ ). 
Table 3: Member State and aggregate results $\left(\tilde{\alpha}_{i}\right.$ defined by the BSA, animal number adjustment factor $\left.\delta=0.15\right)$ for two assumptions regarding $2020 \mathrm{BAU}$ emissions $\left(\hat{E}_{2020, i}\right)$.

\begin{tabular}{|c|c|c|c|c|c|c|c|c|c|c|c|c|}
\hline \multirow[b]{2}{*}{ MS } & \multicolumn{6}{|c|}{$\hat{E}_{2020, i}=E_{2005, i}\left(p^{*}=42.4 € / \mathrm{tCO}_{2} \mathrm{eq}\right)$} & \multicolumn{6}{|c|}{$\hat{E}_{2020, i}=\left(1-\hat{\lambda}_{i}\right) E_{2005, i}\left(\hat{p}^{*}=32.2 € / \mathrm{tCO}_{2} \mathrm{eq}\right)$} \\
\hline & $\begin{array}{c}\alpha_{i}^{*} \\
(\%)\end{array}$ & $\begin{array}{c}C_{i}^{m}\left(\tilde{\alpha}_{i}\right) \\
\left(€ / \mathrm{tCO}_{2} \mathrm{eq}\right)\end{array}$ & $C_{i}\left(\tilde{\alpha}_{i}\right)$ & $\begin{array}{r}C_{i}\left(\alpha_{i}^{*}\right) \\
\quad(\mathrm{M} €\end{array}$ & $T R_{i}$ & $N G_{i}$ & $\begin{array}{c}\hat{\alpha}_{i}^{*} \\
(\%)\end{array}$ & $\begin{array}{c}\hat{C}_{i}^{m}\left(\tilde{\alpha}_{i}\right) \\
\left(€ / \mathrm{tCO}_{2} \mathrm{eq}\right)\end{array}$ & $\hat{C}_{i}\left(\tilde{\alpha}_{i}\right)$ & $\begin{array}{r}\hat{C}_{i}\left(\hat{\alpha}_{i}^{*}\right) \\
(\mathrm{M} €\end{array}$ & $\hat{T R} R_{i}$ & $\hat{N G} G_{i}$ \\
\hline AT & 10.1 & 81.6 & 32 & 11 & 14 & 6 & 10.2 & 67.7 & 23 & 7 & 11 & 6 \\
\hline $\mathrm{BE}$ & 14.4 & 44.9 & 30 & 27 & 3 & 0 & 11.1 & 49.3 & 35 & 17 & 14 & 3 \\
\hline $\mathrm{DE}$ & 8.3 & 80.6 & 290 & 92 & 137 & 60 & 12.2 & 42.7 & 94 & 56 & 32 & 5 \\
\hline DK & 3.5 & 247.3 & 211 & 7 & 62 & 143 & 5.2 & 210.3 & 158 & 4 & 42 & 112 \\
\hline ES & 9.1 & 47.6 & 61 & 50 & 11 & 1 & 0.3 & 92.2 & 195 & 30 & 88 & 77 \\
\hline FI & 7.0 & 88.1 & 33 & 7 & 17 & 9 & 12.5 & 50.2 & 10 & 4 & 5 & 1 \\
\hline FR & 13.3 & 45.6 & 252 & 222 & 28 & 1 & 13.8 & 33.2 & 146 & 139 & 7 & 0 \\
\hline GR & 6.9 & 23.5 & 5 & 16 & -14 & 3 & 9.4 & 0.0 & 0 & 10 & -21 & 11 \\
\hline IE & 8.4 & 95.9 & 146 & 28 & 72 & 45 & 9.1 & 81.8 & 107 & 16 & 52 & 40 \\
\hline IT & 12.0 & 47.1 & 102 & 85 & 16 & 1 & 10.2 & 45.3 & 95 & 54 & 35 & 7 \\
\hline LU & 16.5 & 59.7 & 2 & 1 & 1 & 0 & 20.7 & 29.8 & 1 & 1 & 0 & 0 \\
\hline $\mathrm{NL}$ & 6.6 & 151.7 & 128 & 16 & 52 & 61 & 3.9 & 174.9 & 160 & 10 & 51 & 99 \\
\hline PT & 14.5 & 0.0 & 0 & 19 & -44 & 25 & 11.6 & 0.0 & 0 & 12 & -27 & 15 \\
\hline $\mathrm{SE}$ & 9.6 & 84.6 & 45 & 13 & 21 & 10 & 13.0 & 52.9 & 20 & 8 & 9 & 3 \\
\hline UK & 6.7 & 89.0 & 302 & 62 & 155 & 85 & 9.0 & 68.0 & 173 & 34 & 89 & 50 \\
\hline EU15 & 10.1 & & 1638 & 657 & 531 & 451 & 10.3 & & 1216 & 400 & 386 & 430 \\
\hline $\mathrm{CY}$ & 6.9 & 30.0 & 1 & 1 & -1 & 0 & -0.1 & 66.5 & 3 & 1 & 2 & 1 \\
\hline $\mathrm{CZ}$ & 12.8 & 0.0 & 0 & 20 & -83 & 63 & 16.4 & 0.0 & 0 & 13 & -74 & 61 \\
\hline $\mathrm{EE}$ & 7.4 & 0.0 & 0 & 2 & -9 & 7 & 17.2 & 0.0 & 0 & 1 & -10 & 9 \\
\hline $\mathrm{HU}$ & 5.3 & 0.0 & 0 & 10 & -52 & 42 & 6.6 & 0.0 & 0 & 5 & -43 & 37 \\
\hline LT & 16.1 & 0.0 & 0 & 8 & -34 & 26 & 21.7 & 0.0 & 0 & 5 & -31 & 26 \\
\hline LV & 8.5 & 0.0 & 0 & 3 & -18 & 14 & 9.8 & 0.0 & 0 & 2 & -14 & 12 \\
\hline PL & 8.4 & 0.0 & 0 & 52 & -270 & 218 & 3.2 & 0.0 & 0 & 30 & -158 & 128 \\
\hline SI & 20.4 & 0.0 & 0 & 5 & -18 & 13 & 24.4 & 0.0 & 0 & 4 & -16 & 13 \\
\hline SK & 17.0 & 0.0 & 0 & 10 & -46 & 36 & 22.5 & 0.0 & 0 & 7 & -42 & 35 \\
\hline NMS & 9.9 & & 1 & 111 & -531 & 421 & 8.9 & & 3 & 67 & -386 & 322 \\
\hline EU & 10.1 & & 1639 & 768 & 0 & 871 & 10.1 & & 1219 & 467 & 0 & 752 \\
\hline
\end{tabular}


An important share of the traded volume is made of hot air, which occurs when BAU emissions are lower than the assigned emission target, or using our notations when $i$ is such that $\tilde{\alpha}_{i} \leq \hat{\lambda}_{i}$. The volume of hot air for country $i$ is thus $\left(\hat{\lambda}_{i}-\tilde{\alpha}_{i}\right) E_{0 i}$. Taking the changes in BAU emissions as predicted by GAINS, hot air represents almost $60 \%$ of the transfers. At the country level, this share ranges from $1 \%$ (Greece) to $80 \%$ (Estonia). The highest amounts of hot air are found in Poland (for a value of $99 \mathrm{M} €$ at equilibrium price), the Czech Republic (43 M€), and Hungary (33 M€).

Countries that gain the most from the implementation of a cap-and-trade system compared to the no-flexibility case are of two categories: (i) countries with low abatement costs and generous targets, and (ii) those with high abatement costs and stringent targets. The former gain through the sale of permits (possibly in the form of hot air). The latter save on expensive domestic abatement by buying permits to comply with their commitment. Our results indicate that Poland and the Czech Republic fall in the first category, while Denmark and the Netherlands are in the second one.

\section{Sensitivity analysis}

In this section, we carry out a sensitivity analysis to assess the robustness of the results presented above. We examine the impacts various levels of the overall abatement target for EU agriculture ( $(\tilde{\alpha})$. We also vary the livestock numbers adjustment factor $(\delta)$, which affects the abatement potential and costs for each farm-type. These changes are combined with the two previously used assumptions regarding the rate of decrease in BAU emissions between 2005 and $2020\left(\hat{\lambda}_{i}\right.$ either set to 0 or to the value predicted from GAINS).

The EU climate-energy package contains the provision that, should a significant international agreement on GHG mitigation be reached, the EU overall abatement target would be revised upward from $20 \%$ to $30 \%$. Such a change would certainly affect the overall abatement target for non-ETS emissions, although the details of its implication for the BSA have been left for further negotiations. Moreover, the non-ETS abatement target covers not only agriculture but also all sectors not covered by the EU cap-and-trade system. Therefore, reductions achieved in other sectors will influence the abatement required from agriculture.

We vary the value of $\tilde{\alpha}$ from $0.5 \%$ to $25 \%$ (by step of $0.5 \%$ ). Note that individual country targets $\tilde{\alpha}_{i}$ are changed proportionally so that the relative distribution of the effort is not modified. Aggregate results for $\tilde{\alpha}=5 \%$ and $\tilde{\alpha}=15 \%$ are reported in Table 4 . Most of the qualitative comments made above still hold. The set of Member States which benefit from hot air is quite robust to the chosen value of $\tilde{\alpha}$. Increasing the abatement target from $5 \%$ to $15 \%$ implies an increase in equilibrium emission price from 18.4 to $69.3 € / \mathrm{tCO}_{2} \mathrm{eq}$ if $\mathrm{BAU}$ emissions are assumed to be constant, and from 9.9 to 
Table 4: Aggregate results for two alternative assumptions regarding the EU abatement target $\tilde{\alpha}$ (animal number adjustment factor: $\delta=0.15)$

\begin{tabular}{|c|c|c|c|c|c|c|c|c|c|c|}
\hline & \multicolumn{5}{|c|}{$\hat{E}_{2020, i}=E_{2005, i}$} & \multicolumn{5}{|c|}{$\hat{E}_{2020, i}=\left(1-\hat{\lambda}_{i}\right) E_{2005, i}$} \\
\hline & $\begin{array}{c}p^{*} \\
\left(€ / \mathrm{tCO}_{2} \mathrm{eq}\right)\end{array}$ & $C_{i}\left(\tilde{\alpha}_{i}\right)$ & \multicolumn{2}{|c|}{$(\mathrm{M} €)$} & $N G_{i}$ & $\begin{array}{c}\hat{p}^{*} \\
\left(€ / \mathrm{tCO}_{2} \mathrm{eq}\right)\end{array}$ & $\hat{C}_{i}\left(\tilde{\alpha}_{i}\right)$ & $\begin{array}{r}\hat{C}_{i}\left(\hat{\alpha}_{i}^{*}\right) \\
(\mathrm{N}\end{array}$ & $\begin{array}{l}\hat{T R} R_{i} \\
E)\end{array}$ & $\hat{N G_{i}}$ \\
\hline & \multicolumn{10}{|c|}{$\tilde{\alpha}=5 \%$} \\
\hline EU15 & & 380 & 144 & 114 & 122 & & 242 & 46 & 56 & 140 \\
\hline NMS & & 0 & 23 & -114 & 91 & & 2 & 7 & -56 & 51 \\
\hline \multirow[t]{2}{*}{ EU } & 18.4 & 380 & 167 & 0 & 213 & 9.9 & 244 & 53 & 0 & 191 \\
\hline & \multicolumn{10}{|c|}{$\tilde{\alpha}=15 \%$} \\
\hline EU15 & & 3932 & 1576 & 1307 & 1049 & & 3176 & 1142 & 1053 & 982 \\
\hline NMS & & 2 & 275 & -1307 & 1034 & & 5 & 197 & -1053 & 862 \\
\hline EU & 69.3 & 3934 & 1850 & 0 & 2083 & 57.7 & 3182 & 1338 & 0 & 1843 \\
\hline
\end{tabular}

$57.7 € / \mathrm{tCO}_{2} \mathrm{eq}$ if the expected changes predicted by GAINS are used. Total cost savings are much more sensitive to the choice of the overall target. They are multiplied almost ten times as a result of a tripling of the abatement target, reaching approximately $1840 \mathrm{M} €$ when $\tilde{\alpha}=15 \%$.

The livestock numbers adjustment factor $(\delta)$ defines the admissible range of variation in animal numbers relative to the base situation and, therefore, influences the frontier of mitigation possibilities. Both marginal and total abatement costs are likely to be affected by a change in this parameter. As reducing livestock numbers is one straightforward means of reducing enteric fermentation and manure related GHG emissions, a larger value of $\delta$ is likely to decrease marginal abatement costs, and therefore lead to lower value of the equilibrium price.

We complement the reference simulation $(\delta=0.15)$, with two additional sets of simulations $(\delta=0$ and $\delta=0.3$ ). The case $\delta=0$ corresponds to a situation where animal numbers are fixed to base levels, leaving changes in animal feeding as the only way of mitigating animal related emissions. By contrasting results from this case with that of the reference simulation, one can assess the additional abatement permitted by higher flexibility in adjusting livestock numbers. The resulting country-specific estimated parameters are given in Appendix (Table 6). The main impact of higher values of $\delta$ is to shift the maximum abatement rate $\bar{\alpha}$. The corresponding aggregate results are reported in Table 5. A higher value of $\delta$ tends to decrease marginal and total abatement costs. As an illustration, when changes in BAU emissions are accounted for, increasing $\delta$ from 0 to 0.3 reduces the total cost of the BSA without flexibility instruments by $24 \%$ (from about 1,430 to 1,090 M€) and the equilibrium emission price by $20 \%$ (from 37 to $29.5 € / \mathrm{tCO}_{2}$ eq).

The results of the sensitivity analysis are summarized in Figure 3, which presents the cost-saving 
Table 5: Aggregate results for two alternative values of the animal number adjustment factor $\delta$ (country targets $\tilde{\alpha}_{i}$ defined by the BSA)

\begin{tabular}{|c|c|c|c|c|c|c|c|c|c|c|}
\hline & \multicolumn{5}{|c|}{$\hat{E}_{2020, i}=E_{2005, i}$} & \multicolumn{5}{|c|}{$\hat{E}_{2020, i}=\left(1-\hat{\lambda}_{i}\right) E_{2005, i}$} \\
\hline & $\begin{array}{c}p^{*} \\
\left(€ / \mathrm{tCO}_{2} \mathrm{eq}\right)\end{array}$ & \multicolumn{4}{|c|}{$(\mathrm{M} €)$} & \multicolumn{2}{|l|}{$\left(€ / \mathrm{tCO}_{2} \mathrm{eq}\right)$} & $\begin{array}{r}\hat{C}_{i}\left(\hat{\alpha}_{i}^{*}\right) \\
\quad(\mathrm{M}\end{array}$ & $\hat{T R_{i}}$ & $\hat{N G_{i}}$ \\
\hline & \multicolumn{10}{|c|}{$\delta=0$} \\
\hline EU15 & & 1876 & 755 & 604 & 516 & & 1424 & 460 & 437 & 528 \\
\hline NMS & & 1 & 126 & -604 & 479 & & 3 & 75 & -437 & 365 \\
\hline \multirow[t]{2}{*}{ EU } & 48.8 & 1876 & 881 & 0 & 996 & 37.0 & 1427 & 535 & 0 & 892 \\
\hline & \multicolumn{10}{|c|}{$\delta=0.3$} \\
\hline EU15 & & 1485 & 599 & 481 & 405 & & 1084 & 368 & 353 & 364 \\
\hline NMS & & 1 & 101 & -481 & 381 & & 3 & 61 & -353 & 295 \\
\hline EU & 38.4 & 1486 & 700 & 0 & 786 & 29.5 & 1087 & 429 & 0 & 659 \\
\hline
\end{tabular}

ratio defined as $\left(\sum_{i} C_{i}\left(\tilde{\alpha}_{i}\right)\right) /\left(\sum_{i} C_{i}\left(\alpha_{i}^{*}\right)\right)$ for all the explored values of $\tilde{\alpha}_{i}, \delta$ and $\hat{\lambda}_{i}$. For the whole range of parameter values, this ratio is above 2 , indicating that reaching the same abatement target would be at least twice as expensive if no intra-EU flexibility instruments are adopted. This ratio is even higher when accounting for the expected changes in BAU agricultural emissions between 2005 and 2020. The assumption regarding the animal number adjustment factor has a lesser impact on the cost-saving ratio than the expected change in BAU emissions.

\section{Concluding remarks}

In this text, we have carried out a quantitative assessment of marginal abatement costs of GHG emissions from European agriculture and analyzed the implications of the EU burden sharing agreement for this sector. To do so, a generic specification of MAC curves was proposed. The retained specification provides an alternative to simpler forms previously used in analytical studies. Yet, it enables fairly easy parameterization and numerical computations. A set of parameterized MAC curves for agricultural emissions at the Member State level have been estimated using the outputs of a detailed supply-side model of the European agriculture. Based on these reduced forms, we have assessed the total and marginal abatement costs associated with the BSA, as well as the cost-effective burden sharing and the corresponding equilibrium emission price and abatement costs.

Our findings are threefold. First, the heterogeneity of MAC across Member States stands out as an important feature. As the agreed targets under the BSA do not reflect the heterogeneity of agricultural MAC at the Member State level, the use of flexibility instruments may provide substantial cost-savings 


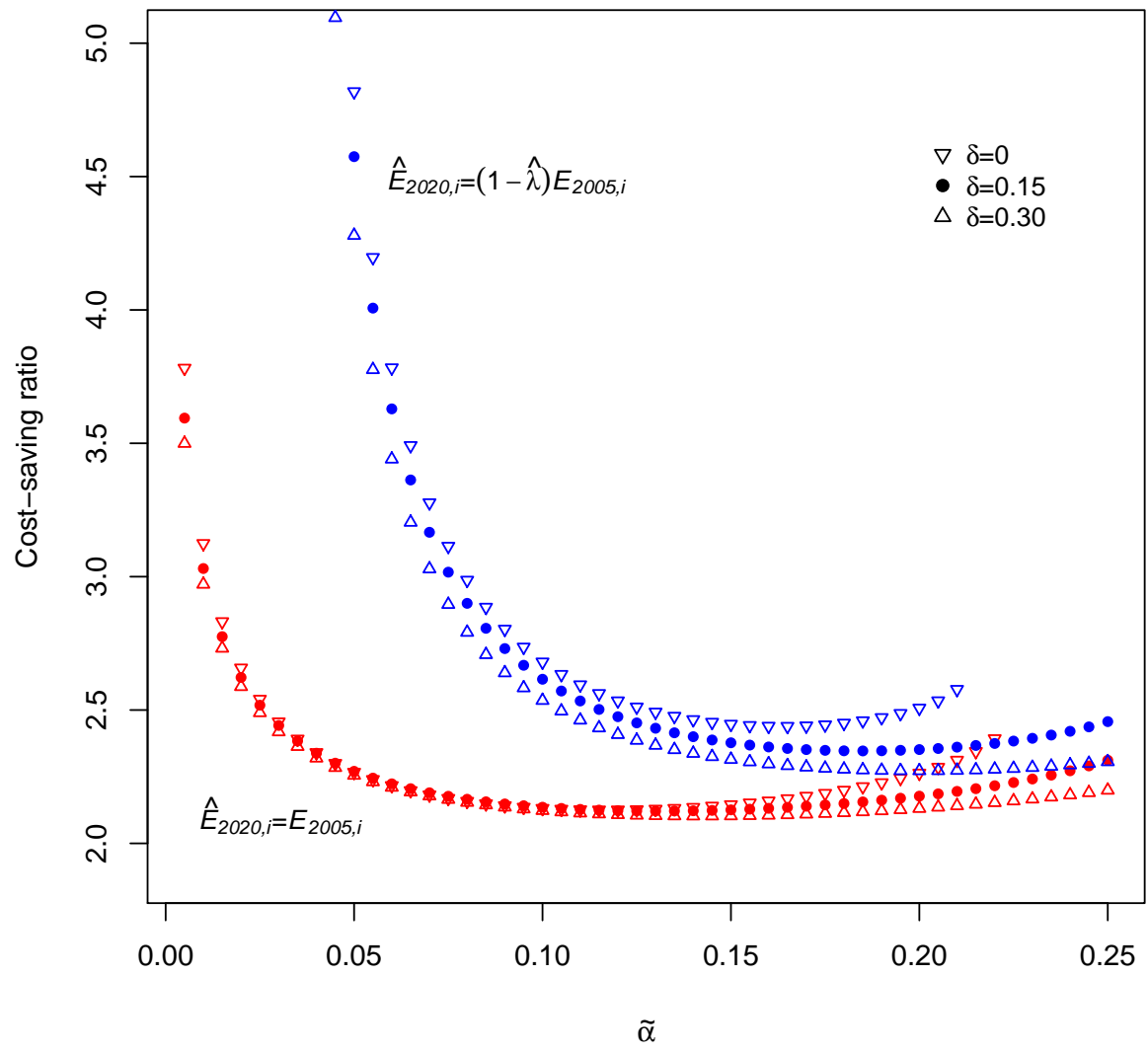

Figure 3: Cost-saving ratio for various assumptions regarding BAU emissions in $2020\left(\hat{E}_{2020, i}\right)$, animal adjustment factor $(\delta)$, and overall abatement target $(\tilde{\alpha})$. 
compared to the strict implementation of each individual country's target. Second, the range of equilibrium emission price at which the EU 10\% reduction target can be reached in European agriculture (32-42 $\left.€ / \mathrm{tCO}_{2} \mathrm{eq}\right)$ is in line with results from analyses covering all non-ETS sectors $\left(40 € / \mathrm{tCO}_{2} \mathrm{eq}\right.$ in Capros et al., 2008; Tol, 2009), and lower than that found in previous studies focusing on EU agriculture (55 and $73 € / \mathrm{tCO}_{2}$ eq in De Cara et al., 2005; Pérez Domínguez et al., 2009, respectively, for an $8 \%$ reduction target). This suggests that the agricultural sector could play an important role in meeting the overall EU target in a cost-effective manner. Third, the use of the BSA targets as a basis for allocating allowances in a cap-and-trade system for agricultural emissions may have important distributional consequences. In particular, this would involve significant amounts of hot air and substantial transfers from EU-15 countries to New Member States. The latter result is of course conditional on the distribution of abatement costs and potential in the other sectors not currently covered by the EU ETS, such as the transport and residential sectors.

As the MAC curves used in this paper are derived from a supply-side model, they do not account for the market responses to reductions in agricultural emissions. Accounting for these would require a partial or general equilibrium approach. The results of the meta-analysis by Vermont \& De Cara (2010) indicate that this would tend to further reduce marginal abatement costs, and thus strengthen the role that agriculture could play in the cost-effective mitigation mix. Lastly, it is sometimes argued that the greater uncertainty that prevails in the accounting of agricultural emissions could impede the inclusion of this sector in a cap-and-trade system (Monni et al., 2007). The cost-savings ratio found in the present paper suggests that it may be worth carefully weighing the extra costs caused by uncertainty and the gains permitted by market-based instruments. Further research is needed in this direction. 


\section{References}

Beach, R. H., DeAngelo, B. J., Rose, S., Li, C., Salas, W., \& DelGrosso, S. J. (2008). Mitigation potential and costs for global agricultural greenhouse gas emissions. Agricultural Economics, 38(2), 109-115.

Böhringer, C., Hoffmann, T., \& de Lara-Peñatec, C. M. (2006). The efficiency costs of separating carbon markets under the EU emissions trading scheme: A quantitative assessment for Germany. Energy Economics, 28(1), 44-61.

Böhringer, C., Löschel, A., Moslener, U., \& Rutherford, T. F. (2009). EU climate policy up to 2020: An economic impact assessment. Energy Economics, 31(Supplement 2), 295-305.

Capros, P., Mantzos, L., Papandreou, V., \& Tasios, N. (2008). Model-based Analysis of the 2008 EU Policy Package on Climate Change and Renewables. Report to DG Environment, E3MLab, National Technical University of Athens, Athens, Greece.

Convery, F. (2009). Origins and development of the EU ETS. Environmental and Resource Economics, $43,391-412$.

De Cara, S., Houzé, M., \& Jayet, P.-A. (2005). Methane and nitrous oxide emissions from agriculture in the EU: A spatial assessment of sources and abatement costs. Environmental and Resource Economics, 32(4), 551-583.

Debove, E. \& Jayet, P. (2007). The Luxembourg agreement seen through the core model. In P.-A. Jayet (Ed.), Report on results concerning models linking farm, markets and the environment, number D4 in Genedec Project (FP6-502184) (pp. 13-27). Grignon, France: UMR Economie Publique INRA. http://www.grignon.inra.fr/economie-publique/genedec/publi/deliv/WP3_D4.pdf.

Eggleston, H., Buendia, L., Miwa, K., Ngara, T., \& Tanabe, K., Eds. (2006). 2006 IPCC Guidelines for National Greenhouse Gas Inventories. Intergovernmental Panel on Climate Change (IPCC). Japan: IGES.

Ellerman, A. \& Buchner, B. (2008). Over-allocation or abatement? A preliminary analysis of the EU ETS based on the 2005-06 emissions data. Environmental and Resource Economics, 41, 267-287.

European Commission (2008). 2020 by 2020: Europe's climate change opportunity. Communication $\operatorname{COM}(2008) 30$ final, Commission of the European Communities, Brussels, Belgium. 
European Commission (2009). The role of European agriculture in climate change mitigation. Commission staff working document SEC(2009) 1093 final, Commission of the European Communities, Brussels.

European Environment Agency (2010a). Annual European Union greenhouse gas inventory 19902008 and inventory report. Technical report 6/2010, European Environment Agency, Copenhagen, Denmark.

European Environment Agency (2010b). Interactive data viewer. Web site, European Environment Agency, Copenhagen, Denmark. http://dataservice.eea. europa. eu/PivotApp/.

European Union (2003). Directive establishing a scheme for greenhouse gas emission allowance trading within the Community and amending Council Directive 96/61/EC. Directive of the European Parliament and of the Council 2003/87/EC, European Commission, Brussels, Belgium. Official Journal of the European Union L275: 32-46.

European Union (2009). Decision on the effort of Member States to reduce their greenhouse gas emissions to meet the Community's greenhouse gas emission reduction commitments up to 2020. Decision 406/2009/EC, The European Parliament and the Council of the European Union, Brussels, Belgium. Official Journal of the European Union L140: 136-138.

Golub, A., Hertel, T., Lee, H.-L., Rose, S., \& Sohngen, B. (2009). The opportunity cost of land use and the global potential for greenhouse gas mitigation in agriculture and forestry. Resource and Energy Economics, 31(4), 299-319.

Hediger, W. (2006). Modeling GHG emissions and carbon sequestration in Swiss agriculture: An integrated economic approach. International Congress Series, 1293, 86-95. Greenhouse Gases and Animal Agriculture: An Update. Proceedings of the 2nd International Conference on Greenhouse Gases and Animal Agriculture (Zurich, Switzerland).

Höglund-Isaksson, L., Winiwarter, W., Wagner, F., Klimont, Z., \& Amann, M. (2010). Potentials and costs for mitigation of non- $\mathrm{CO}_{2}$ greenhouse gas emissions in the European Union until 2030: Results. Report to the European Commission, DG Climate Action Contract no. 07.030700/2009/545854/SER/C5, International Institute for Applied Systems Analysis (IIASA), Laxenburg, Austria.

IIASA (2010). Gains online: Gains Europe. Web site, International Institute for Applied Systems Analysis (IIASA), Laxenburg, Austria. http://gains.iiasa.ac.at/gains/EUR/index . login. 
Lacasta, N., Oberthür, S., Santos, E., \& Barata, P. (2010). From sharing the burden to sharing the effort: Decision 406/2009/EC on Member State Emission Targets for non-ETS sectors, (pp. 93-117). Volume 15 of Oberthür \& Pallemarts (2010).

McCarl, B. A. \& Schneider, U. A. (2001). Greenhouse gas mitigation in U.S. agriculture and forestry. Science, 294, 2481-2482.

Monni, S., Syri, S., \& Pipatti, R. (2007). Extensions of EU emissions trading schemes to other sectors and gases: Consequences for uncertainty of total tradable amount. Water, Air and Soil Pollution: Focus, 4-5, 529-538.

Moran, D., MacLeod, M., Wall, E., Eory, V., McVittie, A., Barnes, A., Rees, R., Topp, C., Pajot, G., Matthews, R., Smith, P., \& Moxey, A. (2010). Developing carbon budgets for UK agriculture, landuse, land-use change and forestry out to 2022. Climatic Change. In press. DOI: 10.1007/s10584010-9898-2.

Newell, R. G. \& Stavins, R. N. (2003). Cost heterogeneity and the potential savings of market-based policies. Journal of Regulatory Economics, 23(1), 43-59.

Oberthür, S. \& Pallemarts, M., Eds. (2010). The New Climate Policies of the European Union, volume 15 of Institute for European Studies - Publication Series. Brussels, Belgium: VUB Press.

Pérez Domínguez, I., Britz, W., \& Holm-Müller, K. (2009). Trading schemes for greenhouse gas emissions from European agriculture: A comparative analysis based on different implementation options. Review of Agricultural and Environmental Studies, 90(3), 287-308.

Schneider, U. A., McCarl, B. A., \& Schmid, E. (2007). Agricultural sector analysis on greenhouse gas mitigation in US agriculture and forestry. Agricultural Systems, 94(2), 128-140.

Smith, P., Martino, D., Cai, Z., Gwary, D., Janzen, H., Kumar, P., McCarl, B., Ogle, S., O’Mara, F., Rice, C., Scholes, B., Sirotenko, O., Howden, M., McAllister, T., Pan, G., Romanenkov, V., Schneider, U., Towprayoon, S., Wattenbach, M., \& Smith, J. (2008). Greenhouse gas mitigation in agriculture. Philosophical Transactions of the Royal Society B: Biological Sciences, 363(1492), 789-813.

Tol, R. S. (2009). Intra-union flexibility of non-ETS emission reduction obligations in the European Union. Energy Policy, 37(5), 1745 - 1752. 
UNFCCC (2008). Challenges and opportunities for mitigation in the agricultural sector. Technical paper FCCC/TP/2008/8, United Nations Framework Convention on Climate Change, Bonn, Germany.

Vermont, B. \& De Cara, S. (2010). How costly is mitigation of non- $\mathrm{CO}_{2}$ greenhouse gas emissions from agriculture? A meta-analysis. Ecological Economics, 69(7), 1373-1386. 
Table 6: Appendix: Results of the non-linear fit of the abatement supply function for two alternative values of the animal number adjustment factor $(\delta)$.

\begin{tabular}{|c|c|c|c|c|c|c|c|c|}
\hline \multirow[b]{2}{*}{ MS } & \multicolumn{4}{|c|}{$\delta=0$} & \multicolumn{4}{|c|}{$\delta=0.3$} \\
\hline & $\begin{array}{l}\bar{\alpha}_{i} \\
(1)\end{array}$ & $\begin{array}{l}\beta_{i} \\
(1)\end{array}$ & $\begin{array}{c}\tau_{i} \\
\left(€ / \mathrm{tCO}_{2} \mathrm{eq}\right)\end{array}$ & $\begin{array}{l}\hat{\sigma} \\
(1)\end{array}$ & $\begin{array}{l}\bar{\alpha}_{i} \\
(1)\end{array}$ & $\begin{array}{l}\beta_{i} \\
(1)\end{array}$ & $\begin{array}{c}\tau_{i} \\
\left(€ / \mathrm{tCO}_{2} \mathrm{eq}\right)\end{array}$ & $\begin{array}{l}\hat{\sigma} \\
(1)\end{array}$ \\
\hline $\mathrm{AT}$ & 0.495 & 0.784 & 289.6 & 0.012 & 0.608 & 0.835 & 319.7 & 0.012 \\
\hline $\mathrm{BE}$ & 0.412 & 0.804 & 148.8 & 0.018 & 0.577 & 0.779 & 179.2 & 0.023 \\
\hline DE & 0.506 & 0.891 & 307.4 & 0.009 & 0.643 & 0.925 & 347.2 & 0.011 \\
\hline DK & 0.447 & 1.049 & 450.1 & 0.009 & 0.578 & 1.154 & 470.7 & 0.012 \\
\hline ES & 0.487 & 0.933 & 267.9 & 0.015 & 0.646 & 0.902 & 301.6 & 0.018 \\
\hline FI & 0.587 & 1.305 & 219.0 & 0.019 & 0.711 & 1.191 & 264.5 & 0.017 \\
\hline FR & 0.605 & 0.831 & 264.1 & 0.008 & 0.727 & 0.849 & 257.9 & 0.013 \\
\hline GR & 0.369 & 0.877 & 456.2 & 0.007 & 0.603 & 1.032 & 249.5 & 0.016 \\
\hline IE & 0.496 & 1.274 & 180.8 & 0.012 & 0.687 & 1.206 & 214.7 & 0.016 \\
\hline IT & 0.561 & 0.757 & 283.7 & 0.010 & 0.696 & 0.831 & 296.9 & 0.010 \\
\hline LU & 0.488 & 0.762 & 192.3 & 0.011 & 0.650 & 0.645 & 210.0 & 0.022 \\
\hline NL & 0.349 & 0.824 & 418.2 & 0.021 & 0.523 & 0.793 & 378.5 & 0.032 \\
\hline $\mathrm{PT}$ & 0.374 & 0.777 & 134.6 & 0.009 & 0.563 & 1.079 & 112.4 & 0.019 \\
\hline SE & 0.500 & 1.043 & 231.5 & 0.014 & 0.639 & 0.961 & 279.2 & 0.011 \\
\hline UK & 0.482 & 1.350 & 192.9 & 0.020 & 0.624 & 1.287 & 209.1 & 0.016 \\
\hline EU15 & 0.517 & 0.885 & 263.5 & 0.007 & 0.661 & 0.906 & 273.3 & 0.007 \\
\hline $\mathrm{CY}$ & 0.448 & 0.914 & 282.8 & 0.024 & 0.621 & 1.033 & 307.4 & 0.030 \\
\hline $\mathrm{CZ}$ & 0.613 & 0.849 & 277.7 & 0.017 & 0.695 & 0.712 & 379.0 & 0.024 \\
\hline $\mathrm{EE}$ & 0.579 & 1.005 & 299.4 & 0.015 & 0.711 & 1.177 & 270.1 & 0.030 \\
\hline HU & 0.631 & 1.204 & 358.3 & 0.018 & 0.738 & 1.222 & 320.2 & 0.013 \\
\hline LT & 0.697 & 0.772 & 247.3 & 0.020 & 0.778 & 0.928 & 217.1 & 0.026 \\
\hline LV & 0.656 & 1.107 & 285.2 & 0.007 & 0.749 & 1.181 & 241.5 & 0.013 \\
\hline PL & 0.586 & 1.067 & 292.7 & 0.011 & 0.706 & 1.140 & 231.5 & 0.009 \\
\hline SI & 0.490 & 0.660 & 119.9 & 0.026 & 0.684 & 0.603 & 250.1 & 0.029 \\
\hline SK & 0.645 & 0.707 & 234.4 & 0.016 & 0.674 & 0.669 & 245.4 & 0.023 \\
\hline NMS & 0.604 & 0.960 & 294.9 & 0.010 & 0.705 & 0.995 & 260.7 & 0.009 \\
\hline EU & 0.529 & 0.894 & 269.2 & 0.006 & 0.667 & 0.919 & 271.5 & 0.006 \\
\hline
\end{tabular}





\section{Working Paper Series}

$n^{\circ} 2011-05$

\section{$n^{\circ} 2011-05$}

Marginal abatement costs of greenhouse gas emissions from European agriculture, cost effectiveness, and the EU non-ETS Burden Sharing Agreement

by Stéphane De Cara and Pierre-Alain Jayet

Irreversible investment, uncertainty, and ambiguity: the case of bioenergy sector

by Pierre-André Jouvet, Elodie Le Cadre and Caroline Orset

Combining cap-and-trade with offsets: lessons from CER use in the EU ETS in 2008 and 2009

by Raphael Trotignon

$n^{\circ} 2011-02$

Tradable pollution permits in dynamic general equilibrium: can optimality and acceptability be reconciled?

by Thierry Bréchet, Pierre-André Jouvet and Gilles Rotillon

$n^{\circ} 2011-01$

$n^{\circ} 2 \cdot$ November 2010
$\mathrm{CO}_{2}$ Prices and Portfolio Management during Phase II of the EU ETS by Maria Mansanet-Bataller

Public and private risk sharing in the financing of low- emitting urban infrastructure projects: the case of CDM projects in the waste sector by Dorothee Teichmann

A two-sector model of the European Union Emissions Trading Scheme? by Suzanne Shaw

\section{$n^{\circ} 1 \bullet$ June 2010}

\section{Contact us : \\ Chaire Economie du Climat - Palais Brongniart (4e étage) \\ 28 Place de la Bourse, 75002 Paris \\ Tel : +33(0)149275634 \\ Fax : +33(0)149275628 \\ Email : contact@chaireeconomieduclimat.org}

